\title{
Hubungan Indeks Massa Tubuh dengan Kadar Gula Darah Puasa pada Mahasiswa Program Studi Kedokteran Universitas Muhammadiyah Jakarta
}

\author{
Tri Wahyuni ${ }^{1 *}$, Anggi Nauli², Gladys Dwiani Tinovella Tubarad ${ }^{2}$, Murni Sri Hastuti \\ Meita Dwi Utami ${ }^{4}$, Tirta Prawita Sari ${ }^{5}$
}

1) Departemen Patologi Klinik, Fakultas Kedokteran dan Kesehatan, Universitas Muhammadiyah Jakarta, Indonesia

2) Program Studi Kedokteran, Fakultas Kedokteran dan Kesehatan, Universitas Muhammadiyah Jakarta, Indonesia

3) Departemen Neurologi, Fakultas Kedokteran dan Kesehatan, Universitas Muhammadiyah Jakarta, Indonesia

4) Departemen Anak, Fakultas Kedokteran dan Kesehatan, Universitas Muhammadiyah Jakarta, Indonesia

5) Departemen Gizi Klinik, Fakultas Kedokteran dan Kesehatan, Universitas Muhammadiyah Jakarta, Indonesia

*Corresponding author: triwahyuni.umj@gmail.com

\begin{abstract}
Background: Obesity is the accumulation of excessive fat that is not normal can be detrimental to health, the body mass index can measure by dividing the weight ( $\mathrm{kg}$ ) and height (m2) to see someone more weight or less. The problem of obesity started in the year 1975 to the year 2016, the estimated population of the entire world's 1.9 billion adults +18 years experience obesity. In Indonesia, the problem of obesity is still significant, one of them being the area of DKI Jakarta (30\%). Obesity can lead to various diseases. This can occur because excess fat in the body can be metabolized into sugar in the blood, causing an increase in blood sugar. If it is left unchecked, hyperglycemia will happen. A state of hyperglycemia can lead to diabetes mellitus. Purposes: To determine the relationship of body mass index and fasting blood glucose level in students of Medicine Universitas Muhammadiyah Jakarta (UMJ) 2018. Methods: This Research is descriptive-analytic with a cross-sectional approach. Sample data collection with the technique of total sampling all students of Medicine UMJ 2018 on A Cirendeu amounted to 109 people. Analysis of the test statistics with the Spearman Rank correlation test $(C I=95 \%$ and $\alpha=5 \%)$. Results: The Spearman Rank test results indicate no significant relationship between Body Mass Index Levels and Fasting Blood Sugar Levels (Rho) with a p-value of 0.07 and a correlation value of 0.22. There is a possibility that if the variable BMI is high, fasting blood sugar levels can also be increased. Conclusion: There is no significant relationship between Body Mass Index and Fasting Blood glucose level in Students of Medicine UMJ 2018.
\end{abstract}

Keywords: fasting blood sugar, body mass index, obesity

\begin{abstract}
ABSTRAK
Latar belakang: Obesitas adalah akumulasi lemak berlebihan yang tidak normal yang dapat merusak kesehatan, hal ini dapat diukur dengan index massa tubuh dengan membagi berat badan $(\mathrm{kg})$ dan tinggi badan $\left(\mathrm{m}^{2}\right)$ untuk melihat seseorang berat badan lebih atau kurang. Masalah obesitas dimulai pada tahun 1975 hingga tahun 2016 ini, diperkirakan 1,9 miliar orang dewasa dari penduduk seluruh dunia usia \pm 18 tahun mengalami kelebihan berat badan. Di Indonesia masalah obesitas masih tinggi salah satunya DKI Jakarta (30\%). Obesitas dapat menyebabkan berbagai penyakit. Hal ini dapat terjadi karena lemak yang berlebih dalam tubuh dapat dimetabolisme menjadi gula dalam darah sehingga menyebabkan peningkatan
\end{abstract}


gula darah, jika hal ini dibiarkan akan terjadi hiperglikemia. Keadaan hiperglikemia ini bisa menyebabkan penyakit diabetes melitus. Tujuan: untuk mengetahui hubungan indeks massa tubuh dengan kadar gula darah puasa pada mahasiswa Program Studi Kedokteran UMJ tahun 2018. Metode: Penelitian ini deskriptif analitik dengan pendekatan cross sectional. Pengambilan data sampel dengan teknik total sampling seluruh mahasiswa Program Studi Kedokteran UMJ 2018 di kampus A Cirendeu berjumlah 109 orang. Analisis uji statistik dengan uji korelasi Rank Spearman (CI =95\% dan $\alpha=5 \%$ ). Hasil: Hasil uji Rank Spearman menunjukkan bahwa tidak terdapat hubungan yang signifikan antara kadar Indeks Massa Tubuh dengan Kadar Gula Darah Puasa dengan nilai p-value adalah 0,07 dan nilai korelasi adalah 0,22. Ada kemungkinan jika variabel kadar IMT tinggi maka kadar Gula Darah Puasa juga bisa tinggi. Simpulan: Tidak terdapat hubungan signifikan antara Indeks Massa Tubuh dengan Kadar Gula Darah Puasa pada Mahasiswa Program Studi Kedokteran UMJ 2018.

Kata kunci: gula darah puasa, index massa tubuh, obesitas

\section{PENDAHULUAN}

Remaja pada usia 10-18 tahun adalah periode rentan gizi yang dipengaruhi oleh banyak faktor. Remaja membutuhkan zat gizi yang baik untuk peningkatan pertumbuhan fisik, namun disaat yang sama remaja cenderung dekat dengan pola hidup yang tidak sehat. Gizi lebih merupakan salah satu dampak yang dapat dialami Remaja dikarenakan pola hidup yang tidak sehat. Berat badan yang berlebihan jika dibandingkan dengan usia atau tinggi badan menjadi tanda Gizi lebih pada remaja. Kegemukan biasanya lebih banyak ditemukan kejadiannya pada remaja perempuan dibanding remaja laki laki. Kegemukan terjadi karena adanya penimbunan lemak yang berlebihan dalam jaringan lemak tubuh (1).

Kegemukan dan obesitas merupakan akumulasi lemak tidak normal atau berlebihan yang dapat merusak kesehatan. Klasifikasi status gizi pada seseorang dapat dilihat dengan mengukur Indeks massa tubuh (IMT). Cara menghitung IMT yaitu berat badan per kuadrat tinggi badan $\left(\mathrm{kg} / \mathrm{m}^{2}\right)$. Obesitas merupakan risiko utama kematian global kelima, dengan kejadian meninggal akibat kelebihan berat badan atau obesitas sebanyak 2,8 juta orang dewasa setiap tahunnya atau sekitar $65 \%$ (2).

Sejak tahun 1975 sampai 2016, kasus obesitas di seluruh dunia meningkat hampir tiga kali lipat. Pada tahun 2016, jumlah yang mengalami kelebihan berat badan lebih dari 1,9 miliar orang dewasa (usia \pm 18 tahun). Enam ratus lima puluh juta orang dewasa mengalami obesitas dan 39\% merupakan berusia 18 tahun ke atas. Saat ini penduduk dunia hidup dalam keadaan dimana kelebihan berat badan dan obesitas dapat membunuh lebih banyak daripada kekurangan berat badan (2).

Prevalensi obesitas di dunia pada tahun 2016 dengan kalangan orang dewasa umur \pm 18 tahun di Amerika Serikat sebesar 40,1\%, Arab Saudi sebesar 35,4\%, Kanada sebesar 33,3\%, Inggris sebesar $27,8 \%$, dan Indonesia sebesar $10 \%$ (2). Di Indonesia, prevalensi masalah obesitas setiap tahunnya terus meningkat. Data prevalensi obesitas Indonesia menunjukan bahwa prevalensi kejadian obesitas di Provinsi Nusa Tenggara Timur adalah terendah $(9,8 \%)$, dan Provinsi Sulawesi Utara tertinggi (36,5\%). Ada beberapa provinsi dengan prevalensi obesitas tinggi 
yaitu Aceh, Bangka Belitung, Sumatera Utara, Riau, DI Yogyakarta, Jawa Timur, Bali, Kalimantan Timur, Maluku Utara, Sulawesi Tengah, Gorontalo, Sulawesi Utara, Papua Barat, Papua dan DKI Jakarta (3).

Masalah obesitas di DKI Jakarta cukup tinggi yaitu sebesar $30 \%$. Faktor penyebab obesitas sebagian besar dikarenakan kebiasaan dan pola hidup masyarakat seperti kebiasaan merokok, stress, sering ngemil, kurangnya olahraga, junk food, kebiasaan minum alkohol. Faktor lain seperti usia, jenis kelamin, dan status sosial ekonomi juga mempengaruhi kejadian obesitas. Berbagai penyakit terkait kegemukan seperti diabetes melitus, hipertensi dan penyakit jantung koroner disebabkan kebiasaan yang tidak sehat tersebut $(1,3)$.

Diabetes Melitus merupakan gangguan metabolik yang disebabkan oleh tidak memadainya sekresi hormon insulin, resistensi insulin atau terganggunya fungsi insulin atau dapat merupakan gabungan dari kedua gangguan tersebut. Keadaan tersebut mengakibatkan peningkatan kadar gula dalam darah. Peningkatan prevalensi Diabetes Melitus sangat erat kaitannya dengan obesitas, dalam beberapa penelitian, Diabetes Melitus dipengaruhi oleh faktor resiko salah satunya obesitas (4).

Antropometri merupakan salah satu metode penilaian status gizi yang sering digunakan. Indeks antropometri yang umum digunakan yaitu berat badan menurut tinggi badan (BB/TB), berat badan menurut umur $(\mathrm{BB} / \mathrm{U})$, tinggi badan menurut umur $(\mathrm{TB} / \mathrm{U})$, lingkar lengan atas (LLA), indeks massa tubuh (IMT), rasio lingkar pinggang pinggul (RLPP) dan tebal lemak bawah kulit (5). Berat badan per tinggi badan dalam meter kuadrat $\left(\mathrm{kg} / \mathrm{m}^{2}\right)$ merupakan cara pengukuran Indeks massa tubuh (IMT) (6).

Menurut penelitian peningkatan penyumbang utama dalam peningkatan kadar gula darah sehingga dapat menyebabkan diabetes melitus adalah berat badan dan obesitas. Hal ini disebabkan, obesitas dan kegemukan dapat mengganggu metabolisme glukosa dan terjadinya resistensi insulin sehingga terjadi peningkatan gula dalam darah $(4,7)$.

Peningkatan kadar gula darah dapat diukur melalui pemeriksaan kadar gula darah. Pemeriksaan kadar gula darah terdiri dari pemeriksaan gula darah sewaktu, gula darah puasa seperti yang digunakan pada penelitian ini dan gula darah 2 jam sesudah makan (8).

Aktifitas yang masih ringan, pola makan dan gaya hidup yang masih kurang baik karena banyak tempat-tempat yang menyediakan makanan cepat saji atau fast food adalah beberapa faktor yang dapat menyebabkan berat badan berlebih dan peningkatan kadar gula darah dan banyak risiko penyakit pada mahasiswa yang baru masuk kuliah semester 1 . Penelitian ini bertujuan untuk mengetahui hubungan indeks massa tubuh dengan kadar gula darah puasa pada Mahasiswa Program Studi Kedokteran.

\section{METODE}

Penelitian ini merupakan penelitian analitik observasional dengan pendekatan cross sectional. Responden berpuasa selama 8 jam sebelum diperiksa kadar gula darah puasa (disampaikan beberapa hari sebelum pemeriksaan) dan berat badan serta tinggi badannya.

Penelitian ini dilakukan di kampus A Fakultas Kedokteran dan Kesehatan Universitas Muhammadiyah Jakarta. Kampus A Ciputat. Penelitian dilakukan 
pada bulan September hingga November 2018. Variabel dependen penelitian ini yaitu kadar gula darah puasa (GDP) serta variabel independen yaitu indeks massa tubuh (IMT).

Indeks massa tubuh (IMT) adalah perbandingan berat badan dengan kuadrat tinggi badan diukur menggunakan Timbangan (berat badan) dan Microtois (tinggi badan). Berat badan dikategorikan kurang apabila $<18,5 \mathrm{~kg} / \mathrm{m} 2$, normal $(18,5$ - 22,9 kg/m2), berat badan lebih (23 $24,9 \mathrm{~kg} / \mathrm{m} 2)$, obesitas I ( $25-29,9 \mathrm{~kg} / \mathrm{m} 2)$, obesitas II (> $30 \mathrm{~kg} / \mathrm{m} 2)$. Kadar gula darah diukur menggunakan glucometer, dengan kategori bukan DM apabila gula darah < $90 \mathrm{mg} / \mathrm{dL}$, belum pasti DM apabila 90 - 99 $\mathrm{mg} / \mathrm{dL}, \mathrm{DM}$ apabila $>100 \mathrm{mg} / \mathrm{dL}$.

Populasi dalam penelitian ini adalah mahasiswa Program Studi Kedokteran FKK UMJ angkatan tahun 2018 yang berada di kampus A Cirendeu berjumlah 109 orang. Pengambilan jumlah sampel penelitian menggunakan rumus Slovin dikarenakan jumlah populasi telah diketahui, maka didapatkan minimal sampel berjumlah 68 responden.

Kriteria inklusi penelitian ini yaitu seluruh mahasiswa angkatan 2018 Program Studi Kedokteran FKK UMJ di kampus A Ciputat yang menandatangani lembar persetujuan inform consent sebagai pernyataan bahwa bersedia menjadi responden. Kriteria eksklusi yaitu adanya riwayat penyakit maag atau memiliki riwayat penyakit keluarga Diabetes Melitus dan tidak hadir dalam pengambilan data. Penelitian ini telah mendapatkan surat persetujuan kaji etik dari Komisi Etik Penelitian Kesehatan Fakultas Kedokteran dan Kesehatan, Universitas Muhammadiyah Jakarta, Indonesia dengan nomor 286/PE/KE/FKK/ $\mathrm{UMJ} / \mathrm{X} / 2018$.

\section{HASIL}

Berdasarkan tabel 1 diketahui bahwa $70,6 \%$ dari total keseluruhan sampe merupakan perempuan. Persentase umur 18 tahun paling banyak yaitu sebesar 73,5 $\%$. Tinggi badan sebesar $50 \%$ pada rentang 150-160 cm dan untuk berat badan pada rentang 61-70 kg sebesar 27,9\%. Pada variabel IMT, responden dengan IMT normal sebanyak 38,2 \%. 86,8\% responden dengan GPL Bukan DM.

Tabel 1. Karakteristik Sampel Mahasiswa Program Studi Kedokteran FKK UMJ Angkatan Tahun 2018

\begin{tabular}{|c|c|c|}
\hline Karakteristik & $\begin{array}{l}\text { Frekuensi } \\
\text { (n) }\end{array}$ & $\begin{array}{c}\text { Persentase } \\
(\%)\end{array}$ \\
\hline \multicolumn{3}{|l|}{ Jenis Kelamin } \\
\hline Laki - Laki & 20 & 29,4 \\
\hline Perempuan & 48 & 70,6 \\
\hline \multicolumn{3}{|l|}{ Umur } \\
\hline 18 tahun & 50 & 73,5 \\
\hline 19 tahun & 17 & 25,0 \\
\hline 24 tahun & 1 & 1,5 \\
\hline \multicolumn{3}{|l|}{ Tinggi Badan } \\
\hline$<150$ & 10 & 14,7 \\
\hline $150-160$ & 34 & 50,0 \\
\hline $161-170$ & 16 & 23,5 \\
\hline $171-180$ & 7 & 10,3 \\
\hline$>180$ & 1 & 1,5 \\
\hline \multicolumn{3}{|l|}{ Berat Badan } \\
\hline $40-50$ & 18 & 26,5 \\
\hline $51-60$ & 19 & 27,9 \\
\hline $61-70$ & 15 & 22,1 \\
\hline $71-80$ & 11 & 16,2 \\
\hline$>80$ & 5 & 7,4 \\
\hline \multicolumn{3}{|l|}{ IMT } \\
\hline $\begin{array}{l}<18,5 \\
\text { (Underweight) }\end{array}$ & 5 & 7,4 \\
\hline $\begin{array}{l}18,5-22,9 \\
(\text { Normal) }\end{array}$ & 26 & 38,2 \\
\hline $\begin{array}{l}23,0-24,9 \\
\text { (Overweight) }\end{array}$ & 14 & 20,6 \\
\hline $\begin{array}{l}25,0-29,9 \\
(\text { Obesitas 1) }\end{array}$ & 16 & 23,5 \\
\hline $\begin{array}{l}>30 \\
\text { (Obesitas 2) }\end{array}$ & 7 & 10,3 \\
\hline \multicolumn{3}{|c|}{ Gula Darah Puasa } \\
\hline Bukan DM & 59 & 86,8 \\
\hline Belum Pasti & 9 & 13,2 \\
\hline
\end{tabular}


$\mathrm{DM}$

$\mathrm{DM}$ 0 0

Tabel 2. Hubungan Indeks Massa Tubuh dengan Kadar Gula Darah Puasa Mahasiswa Program Studi Kedokteran FKK UMJ Angkatan Tahun 2018

\begin{tabular}{|c|c|c|c|c|c|c|c|c|c|c|}
\hline \multirow{3}{*}{$\begin{array}{c}\text { IMT } \\
\text { Underweight }\end{array}$} & \multicolumn{8}{|c|}{ Gula Darah Puasa } & \multirow{3}{*}{$\begin{array}{c}\text { Nilai } \\
\text { Korelasi }\end{array}$} & \multirow{3}{*}{$\begin{array}{c}\mathrm{P} \\
\text { value }\end{array}$} \\
\hline & \multicolumn{2}{|c|}{ Bukan DM } & \multicolumn{2}{|c|}{ Belum Pasti DM } & \multicolumn{2}{|c|}{$\mathrm{DM}$} & \multicolumn{2}{|c|}{ Total } & & \\
\hline & 4 & $80,0 \%$ & 1 & $20,0 \%$ & 0 & $0 \%$ & 5 & $100 \%$ & & \\
\hline Normal & 26 & $100 \%$ & 0 & $0 \%$ & 0 & $0 \%$ & 26 & $100 \%$ & & \\
\hline Overweight & 12 & $85,7 \%$ & 2 & $14,3 \%$ & 0 & $0 \%$ & 14 & $100 \%$ & 0,22 & 0,07 \\
\hline Obesitas 1 & 12 & $75,0 \%$ & 4 & $25,0 \%$ & 0 & $0 \%$ & 16 & $100 \%$ & & \\
\hline Obesitas 2 & 5 & $71,4 \%$ & 2 & $28,6 \%$ & 0 & $0 \%$ & 7 & $100 \%$ & & \\
\hline
\end{tabular}

Sebagian besar mahasiswa memiliki kadar IMT normal dengan kadar GDP Bukan DM sebanyak 26 mahasiswa pada Tabel 2. Data tersebut diuji menggunakan Rank Spearman (Rho), diperoleh nilai $\mathrm{p}$-value $=$ 0,07 dengan nilai $\alpha=0,05$ dan nilai $\rho$ (nilai korelasi $)=0,22$. P-value lebih besar dari nilai $\alpha$ maka artinya tidak terdapat hubungan yang signifikan antara Kadar Indeks Massa Tubuh dengan Kadar Gula Darah Puasa Pada Mahasiswa Program Studi Kedokteran FKK UMJ Angkatan Tahun 2018. Nilai korelasi menunjukkan yaitu kedua hubungan variabel berkorelasi sedang.

\section{PEMBAHASAN}

Hasil pada tabel 1 menjelaskan bahwa $70,6 \%$ responden merupakan perempuan dan laki - laki hanya sebesar 29,4\%. Jenis kelamin bisa menjadi faktor dalam kegemukan. Hal ini sejalan dengan penelitian yang menemukan bahwa jenis kelamin perempuan relatif lebih tinggi mengalami kegemukan dibanding laki laki (1). Pada variabel umur sebagian besar responden berusia sekitar 18 tahun sebanyak 50 mahasiswa $(73,5 \%)$. Hal ini dikarenakan umur remaja merupakan periode rentan gizi karena memerlukan kebutuhan zat gizi lebih tinggi namun cenderung memiliki kebiasaan pola makan yang kurang baik (1). Hasil distribusi IMT sebagian besar sampel memiliki kadar IMT normal, hasil ini menunjukan bahwa rata - rata kadar IMT pada mahasiswa masih terbilang baik. Pada distribusi GDP $86,8 \%$ sampel memiliki kadar GDP bukan DM.

Hasil pada tabel 2 mengenai hubungan kadar indeks massa tubuh dengan kadar gula darah puasa pada sampel yaitu 26 mahasiswa mengalami IMT normal dan GDP bukan DM, jumlah ini lebih banyak dibandingkan dengan mahasiswa yang mengalami obesitas 2 yaitu 5 mahasiswa dengan GDP bukan DM. Hasil uji menghasilkan tidak terdapat hubungan yang signifikan antara kadar indeks massa tubuh dengan kadar gula darah puasa. Hal ini didukung oleh hasil penelitian lain dengan hasil yang sama yaitu tidak ada hubungan antara indeks massa tubuh dengan kadar gula puasa yang dilakukan di Poli Gizi RSUD Dr Saiful Anwar Malang (9). Hasil penelitian ini juga sesuai dengan penelitian pada pegawai sekretariat di Riau tahun 2014 dengan hasil tidak ada hubungan antara indeks massa tubuh dengan kadar gula 
darah puasa (10). Menurut penelitian Astuti, yang mempengaruhi kadar glukosa adalah kepatuhan mengkonsumsi obat, kepatuhan diet, konsumsi lemak, pengetahuan terkait Diabetes Mellitus dan dukungan keluarga positif (11).

Hasil penelitian ini bertolak belakang dengan penelitian yang dilakukan pada tahun 2018 yang menemukan bahwa ada hubungan antara status gizi atau IMT dengan kadar gula dalam darah (12). Penelitian lain menyebutkan bahwa obesitas akan terjadi apabila produksi resistin meningkat, hal ini akan mengganggu kerja insulin sehingga mendorong resistensi insulin. Obesitas, menyebabkan hormon adiponektin yang berfungsi meningkatkan sensitivitas terhadap insulin dan meningkatkan efek insulin, mengalami penurunan. Selain jaringan lemak dapat mengeluarkan asam lemak yang apabila menumpuk abnormal di otot dapat mengganggu kerja insulin otot (13). Peningkatan berat badan dan obesitas merupakan penyumbang utama dalam peningkatan kadar gula darah sehingga dapat menyebabkan peningkatan kadar gula darah dan meningkatkan risiko diabetes melitus (14).

Ada kemungkinan jika variabel kadar IMT tinggi maka kadar GDP juga bisa tinggi melihat korelasi Rank Spearman (Rho) pada hubungan kedua variabel sempurna antara variabel IMT dengan variabel GDP meski berkorelasi sangat lemah.

\section{SIMPULAN}

Tidak ada hubungan yang signifikan antara Kadar Indeks Massa Tubuh dengan Kadar Gula Darah Puasa namun ditemukan arah kekuatan korelasi nya positif yang berarti ada kemungkinan jika variabel kadar IMT tinggi maka kadar GDP juga bisa tinggi.

\section{UCAPAN TERIMA KASIH}

Penulis menyampaikan terima kasih kepada Fakultas Kedokteran dan Kesehatan Universitas Muhammadiyah Jakarta yang telah memberikan izin penelitian.

\section{KONFLIK KEPENTINGAN}

Penulis menyatakan tidak memiliki konflik kepentingan.

\section{REFERENSI}

1. Kurdanti W, Suryani I, Syamsiatun NH, Siwi LP, Adityanti MM, Mustikaningsih D, et al. Faktorfaktor yang mempengaruhi kejadian obesitas pada remaja. J Gizi Klin Indones [Internet]. 2015 Apr 30;11(4):179. Available from: https://jurnal.ugm.ac.id/jgki/article/ view/22900

2. World Health Organization. Noncommunicable diseases: Risk factors [Internet]. 2018 [cited 2018 Sep 11]. Available from: https://www.who.int/data/gho/data/t hemes/topics/topic-

details/GHO/ncd-risk-factors

3. Kementerian Kesehatan Republik Indonesia. Laporan Nasional Riset Kesehatan Dasar (Riskesdas) 2013. Jakarta; 2013.

4. Nangge M, Masi G, Oroh W. Hubungan Obesitas Dengan Kejadian Diabetes Melitus. ejournal Keperawatan (e-Kp). 2018;6(1):6.

5. Fitri MO. Aplikasi Monitoring Perkembangan Status Gizi Anak Dan Balita Secara Digital Dengan Metode Antropometri Berbasis Android. J Instek. 2017;2(2):140-9.

6. Tandean N, Mewo Y, Wowor PM. 
Gambaran Indeks Massa Tubuh Pada Anggota Senat Mahasiswa Fakultas Kedokteran Manado. J eBiomedik. 2015;3(3):23-7.

7. Dalawa FN, Kepel B, Hamel R. Hubungan Antara Status Gizi dengan Kadar Gula Darah Puasa Pada Masyarakat Kelurahan Bahu Kecamatan Malalayang Manado. ejournal Keperawatan (e-Kp). 2013;1(1):1-8.

8. Auliya P, Oenzil F, Dia Rofinda ZD. Gambaran Kadar Gula Darah pada Mahasiswa Fakultas Kedokteran Universitas Andalas yang Memiliki Berat Badan Berlebih dan Obesitas. J Kesehat Andalas [Internet]. 2016 Sep 1;5(3). Available from: http://jurnal.fk.unand.ac.id/index.ph p/jka/article/view/571

9. Suryanti SD, Raras AT, Dini CY, Ciptaningsih AH. Hubungan Indeks Massa Tubuh dengan Kadar Gula Darah Puasa pada Pasien Diabetes Melitus Tipe 2. Poltekita J Ilmu
Kesehat. 2019;13(2):86-90.

10. Arif M, Ernalia Y, Rosdiana D. Hubungan Indeks Massa Tubuh dengan Kadar Gula Darah Puasa pada Pegawai Sekretariat Daerah Provinsi Riau. J Online Mhs. 2017;4(2).

11. Astuti CM, Setiarini A. FaktorFaktor yang Berhubungan dengan Pengendalian Kadar Glukosa Darah Pasien Diabetes Melitus Tipe 2 Rawat Jalan di Poliklinik Penyakit Dalam RSJ Prof.Dr.Soerojo Magelang Tahun 2013. Universitas Indonesia; 2013.

12. Masruroh E. Hubungan Umur dan Status Gizi dengan Kadar Gula Darah Penderita Diabetes Melitus Tipe Ii. J Ilmu Kesehat. 2018;6(2):153.

13. Sherwood L. Fisiologi Manusia dari Sel ke Sistem. Jakarta: EGC; 2011.

14. Fatimah RN. Diabetes Melitus Tipe 2. J Kedokt Univ Lampung. 2016;4(5):93-101. 